\title{
THE UPPER NILRADICAL CONNECTED WITH A RIGHT IDEAL IN THE RING $(\mathrm{z}[\sqrt{3}],+, \cdot)$
}

\author{
Azir Jusufi \\ State University of Tetovo, Tetovo, Republic of Macedonia \\ Email: azir.jusufi@unite.edu.mk \\ Murat Sadiku \\ South East European University, Tetovo, Republic of Macedonia \\ Email: m.sadiku@seeu.edu.mk \\ Kristaq Filipi \\ Polytechnic University of Tirana, Tirana, Republic of Albania \\ Email: f_kristaq@hotmail.com \\ DOI: 10.2478/v10306-012-0019-0
}

\begin{abstract}
In addition to theoretical investigations of radicals connected with a right ideal in associative rings, we seek to build models implementing the achieved results. In the process, we succeeded in building an upper nilradical connected with a right ideal in the ring $(\mathrm{Z}[\sqrt{3}],+, \cdot)$. This is presented in the paper, after some necessary theoretical preliminaries.
\end{abstract}

Key words: the ring, right ideal, nilradical, upper nilradical.

\section{Abstrakt}

Krahas hulumtimeve teorike për radikalet e unazave asociative lidhur me një ideal të djathtë kemi synuar të ndërtojmë modele të implementimit të rezultateve të arritura. Në këtë proces është arritur të ndërtohet një radikal i sipërm lidhur me një ideal të djathtë në unazën $(Z[\sqrt{3}],+, \cdot)$, i cili paraqitet në këtë punim pas një parashtrimi teorik të nevojshëm 


\section{Апстракт}

Покрај теоретското истражување за радикалите сврзани со еден десен идеал во асоцијативните прстени, за цел имавме да конструктираме модели на имплементација на теоретското достигнување. Во овој процес, успеавме да конструираме еден конкретен горен нилрадикал на прстенот $(Z[\sqrt{3}],+, \cdot)$ сврзан со еден десен идеал, кој го презентираме во овој труд одкако ќе ја претставиме потребната теорија.

\section{Introduction}

\section{The meaning of radical}

Some properties of the rings vary from known properties, so we encounter difficulties in their classification. Herein lies the reason to seek the definition of a part of the ring about certain properties, part that will be called radical ring.

Let $I_{1}, I_{2}$ be sub rings of the ring $R$. With the sum, marked as $I_{1}+I_{2}$, we understand the set that contains all sums $i_{1}+i_{2}$, where $i_{1} \in I_{1}, i_{2} \in I_{2}$. So, $I_{1}+I_{2}=\left\{i_{1}+i_{2} / i_{1} \in I_{1}, i_{2} \in I_{2}\right\}$.

At first let be examined these propositions:

Proposition 1.1. ([5], pg.397). If $I_{1}, I_{2}$ are ideals of the ring $R$, then

$$
I_{1}+I_{2}=\left\{i_{1}+i_{2} / i_{1} \in I_{1}, i_{2} \in I_{2}\right\} \text { is ideal of } R \text {. }
$$

Let be now $I_{1}, I_{2}, \ldots, I_{k}, \ldots$ (not necessarily a finite number) a sub rings set of the ring $R$. With the sum, marked as $\sum_{k} I_{k}$, we understand the set that contains all sums $i_{1}+i_{2}+\ldots+i_{k}+\ldots$, where $i_{k} \in I_{k}$, so, $\sum_{k} I_{k}=\left\{i_{1}+i_{2}+\ldots+i_{k}+\ldots / i_{1} \in I_{1}, i_{2} \in I_{2}, \ldots\right\}$.

Based on the above we take this: 
Proposition 1.2. ([2], pg.4). The sum of every ideals set of a ring is its ideal.

Let $\gamma$ be a class of the rings such that:

a) $\gamma$ is homomorphic closed: i.e. $A \in \gamma$ and $\varphi: A \rightarrow B$ is homomorphism, follows that $B \in \gamma$.

b) For every ring $A$, the sum $\gamma(A)=\sum(I \triangleleft A \mid I \in \gamma)$ is in $\gamma$.

c) $\gamma(A / \gamma(A))=0$, for every ring $\mathrm{A}$.

Definition 1.1. A ring class $\gamma$ that satisfies the conditions a), b), c), is called radical class. $\gamma(A)$ is called $\gamma$-radical of $A$. The ring $A$ is called $\gamma$-radical ring if $A \in \gamma \Rightarrow \gamma(A)=A$ ([7], pg 53).

The conditions a), b), c) are essential conditions to give the definition of the radicals. To tell if these conditions are satisfied or not for some rings classes is not an easy task. For this reason we aim to find equivalent conditions with them.

Proposition 1.3. ([1], pg.22). If conditions a) and b) apply in a class rings $\gamma$, then the condition c) is equivalent with:

$\bar{c}$ ) If $I$ is ideal of the $\operatorname{ring} A$ and if $I$ and $A / I$ are in $\gamma$, then the $A$ is in $\gamma$.

When the class of the rings $\gamma$ satisfies the condition $\bar{c}$ ) we say that $\gamma$ is closed in connection to extensions.

Proposition 1.4. ([1], pg.23). If conditions a) and $\bar{c}$ ) apply in a rings class $\gamma$, then the condition $b$ ) is equivalent with:

$\bar{b}$ ) If $I_{1} \subseteq I_{2} \subseteq \ldots \subseteq I_{\lambda} \subseteq \ldots$ is an increasing sequence of ideals of a ring $A$, and if every of $I_{\lambda}$ is in $\gamma$ then $\sum_{\lambda} I_{\lambda}$ is in $\gamma$.

When the class of the rings $\gamma$ satisfies the condition $\bar{b}$ ) we say that $\gamma$ is with inductive property. 
From the above propositions we get:

Theorem 1.1. ([1], pg.23). The class of rings $\gamma$ is radical class then and only then when:
a) $\gamma$ is homomorphic closed
$\bar{b}) \gamma$ has the inductive property
$\bar{c}) \gamma$ is closed in connection to extensions.

\section{Nilrings and nilradical}

Definition 2.1. The element $x$ of the ring $R$ is called nilpotent if $\exists n \in N, x^{n}=0$ ( $\square$ is the set of positive whole numbers). The ring $R$ is called nilring if every element of it is nilpotent. The ideal $I$ of the ring $R$ is called nilideal of $R$ if $I$ is nilring.

We mark with $s$ the property: $\forall x \in R, \exists n \in N, x^{n}=0$. The property $s$ is called nilproperty. In these conditions, we can say that nilring is the ring $R$ that satisfies the nilproperty s. Such a ring is called s-ring ([8], pg.69).

Lemma 2.1. ([2], pg.19).

a) If $R$ is nilring then every subring and every homomorphic image of $R$ is nilring.

b) If $I$ is ideal of $R$ and $I, R / I$ are nilrings, then $R$ is nilring.

Lemma 2.2. The sum of two nilideals is nilideal.

Proof. Let $I$ and $J$ be nilideals in $R$. Based on the second theorem on isomorphisms we have: $(I+J) / J \cong I /(I \cap J)$, where $(I+J) / J$ is nilideal from lemma 1.ii., whereas $I /(I \cap J)$ is nilideal as homomorphic image of $I$. Since $I, J,(I+J) / J$ are nilideals then it follows that $I+J$ is nilideal.

Based on lemma 2.2 with mathematical induction is proved this:

Corollary 2.1. The finite sum of nilideals is nilideal. 
From the above come true this:

Lemma 2.3. ([2], pg.19). The sum of a whatever set of nilideals of $R$ is nilideal of $R$.

In the following we show that the class $S$ of $s$-rings is radical class.

a) From lemma 2.1.i. follows that every homomorphic image of a s-ring is s-ring, i.e. the class $S$ is homomorphic closed.

$\bar{c}$ ) From lemma 2.1.ii follows that, if $I$ is ideal of $R$ and $I, R / I$ are in $S$, then $R$ is in $S$ as well. This shows that the class $S$ is closed in connection to extensions.

b) From lemma 2.3 follows that, for every $\operatorname{ring} R, S(R)=\sum(I \triangleleft R \mid I \in S)$ is in the class $S$.

Based on proposition 4 of the point 1 follows that the above condition b) is equivalent with:

$\bar{b}$ ) If $I_{1} \subseteq I_{2} \subseteq \ldots \subseteq I_{\lambda} \subseteq \ldots$ is an increasing sequence of nilideals of the ring $R$, then the sum is $\sum_{\lambda} I_{\lambda}$ in $S$.

As a result of the theorem of the point 1 we get this:

Theorem 2.1. The class $S$ is radical class.

This theorem shows that $S(R)$ is radical of the nilring $R . S(R)$ is called nilradical of the ring $R$. From the above points $b$ ) and $\bar{b}$ ) follows that $S(R)$ is larger nilideal of the ring $R$.

Definition 2.2. The largest nilideal of the nil ring $R$ is called upper nilradical or nilradical of Köthe and is marked as $K(R)$.

Conclusion 2.1 ([3], pg.47). In every ring $R$, the sum of a set of its nilideals is nilideal of $R$. Therefore, in every ring $R$ exists the upper nilradical $K(R)$ and complies with the sum of all nilideals of the ring $R$. If $I$ is ideal in the ring $R$, then $K(I)=I \cap K(R)$. For every ring $R$, the factor-ring $R / K(R)$, there isn't nonzero nilideals, therefore $K(R / K(R))=0$. 
Definition 2.3. The ring $R$ is called $K$-radical, if $R=K(R)$. The ring $Q$ is called semi simple $K$, if $K(Q)=0$.

Theorem 2.2. ([3], pg.47). The ring $R$ is $K$-radical then and only then, when it is nilring. The ring $Q$ is semi simple- $K$ then and only then, when it hasn't nonzero nilideals. Every ideal in the ring $K$-radical or semi simple-K is respectively ring $K$-radical or semi simple- $K$.

\section{The upper nilradical connected with a right ideal}

Referring to the above treatment of nilradical of a ring, we presented a theoretical study on the meaning of the upper nilradical connected with a one-sided ideal of a ring. The study will be concentrated on the right ideal, since the theory of the left ideal of a ring is constructed in an analogous way.

Let $P$ be right ideal in the ring $R$.

Definition 3.1. ([6], pg.43) The ring $R$ is called nilring connected with a right ideal $P$, if all of its elements are nilpotent connected with a right ideal $P$, i.e.

$$
\forall a \in R, \exists n \in N, n \geq 2 \mid a^{n} \in P
$$

The ideal $I$ of ring $R$ is called nilideal connected with a right ideal $P$, if $I$ is nilring connected with a right ideal $P$. In analogous way is given the meaning of the nil subring connected with a right ideal $P$ and the right (left) nilideal connected with a right ideal $P$.

Let $R$ be a nilring connected with a right ideal $P$ and $\phi$ a $P$-homomorphism in $R$ ([11], pg.30). Since $\forall x \in R, \exists n \in \mathrm{N}, x^{n} \in P$ and $\phi\left(x^{n}\right)=[\phi(x)]^{n} \in P$, then $P$-homomorphic image $\phi(R)$ is nilring connected with a right ideal $P$.

We have proved this: 
Theorem 3.1. Every $P$-homomorphic image of a nilring connected with a right ideal $P$ is also nilring connected with a $P$.

Meanwhile are even worth these theorems:

Theorem 3.2. ([10], pg.78) If the ideal $I$ is nilideal connected with a right ideal $P$ in $R$ and the factor-ring $R / I$ is nilring, then $R$ is nilring connected with a right ideal $P$.

Theorem 3.3. ([4], pg.114). The sum of two nilideals connected with a right ideal $P$ is nilideal of the right ideal $P$.

Based on proposition 4 of the point 1 derives that the above condition c) is equivalent with: $\bar{c}$ ) If $I_{1} \subseteq I_{2} \subseteq \ldots \subseteq I_{\lambda} \subseteq \ldots$ is an increasing sequence of nilideals connected with a right ideal $\mathrm{P}$ of $A$ then the $\operatorname{sum} \sum_{\lambda} I_{\lambda}$, is nilideal connected with a right ideal $\mathrm{P}$.

Having in mind the meaning of the Köthe nilradical we give this:

Definition 3.2. The upper nilradical connected with a right ideal $P$ in the $\operatorname{ring} R$ is called the largest nilideal connected with a right ideal $P$ in it. It is marked as $K(R, P)$.

Conclusion 3.1. ([6],[9]) In a ring $R$, the sum of every finite set of nilideals connected with a right ideal $P$ is nilideal connected with a right ideal $P$. After, in every ring $R$, exists the upper nilradical $K(R, P)$ connected with a right ideal $P$ and it complies with the sum of all nilideals connected with a right ideal $P$. If $I$ is ideal connected with a right ideal $P$ of ring $R$, then

$$
K(I, P)=I \cap K(R, P) .
$$

Definition 3.3. The ring $R$ is called $K$-radical connected with a right ideal $P$, if $R=K(R, P)$. 


\section{The upper nilradical connected with a right ideal in the ring $(Z[\sqrt{3}],+, \cdot)$}

Let $\mathrm{Z}[\sqrt{3}]$ be a set of numbers $x=a+b \sqrt{3}$ such that $a, b$ are whole numbers, so

$$
\mathrm{Z}[\sqrt{3}]=\{a+b \sqrt{3} \mid a, b \in \mathrm{Z}\}
$$

Since,

- $x+y=(a+b \sqrt{3})+(c+d \sqrt{3})=(a+c)+(b+d) \sqrt{3} \in Z[\sqrt{3}]$ and

- $x y=(a+b \sqrt{3}) \cdot(c+d \sqrt{3})=(a c+3 b d)+(a d+b c) \sqrt{3} \in Z[\sqrt{3}]$.

Imply $(Z[\sqrt{3}],+, \cdot)$ is algebraic structure, and since

- $x-y=(a+b \sqrt{3})-(c+d \sqrt{3})=(a-c)+(b-d) \sqrt{3} \in Z[\sqrt{3}]$.

Follows that $(\mathrm{Z}[\sqrt{3}],+, \cdot)$ is sub ring of the ring $R$ of the real numbers.

We note $P[\sqrt{3}]$ the set $\{a+b \sqrt{3} \mid a=2 r, b=2 s \wedge r, s \in \mathrm{Z}\}$.

It is clear that $p \in P[\sqrt{3}] \Leftrightarrow p=2(r+s \sqrt{3})$, where $r, s \in Z \Leftrightarrow p=2 x$, where $x \in Z[\sqrt{3}]$.

Therefore, $P[\sqrt{3}]=\{2 x / x \in Z[\sqrt{3}]\}$.

Proposition 4.1. The set $P[\sqrt{3}]$ is right ideal of the $\operatorname{ring}(\mathrm{Z}[\sqrt{3}],+, \cdot)$.

Indeed, since $Z[\sqrt{3}]$ is ring we have:

1. $\forall p_{1}, p_{2} \in P[\sqrt{3}]$, i.e. $p_{1}=2 x_{1}, p_{2}=2 x_{2}$, where $x_{1}, x_{2} \in Z[\sqrt{3}]$, we get

$$
p_{1}-p_{2}=2\left(x_{1}-x_{2}\right) \in P[\sqrt{3}] \text {, because } x_{1}-x_{2} \in Z[\sqrt{3}]
$$

2. $\forall p \in P[\sqrt{3}], \forall y \in Z[\sqrt{3}], p \cdot y=2 x y \in P[\sqrt{3}]$, because $x y \in Z[\sqrt{3}]$.

We note $\mathrm{N}(Z[\sqrt{3}], P[\sqrt{3}])$ the set of numbers $x \in Z[\sqrt{3}]$ such that $x^{n} \in P[\sqrt{3}]$ for every natural number $n \geq 2$, i.e.

$$
\mathrm{N}(Z[\sqrt{3}], P[\sqrt{3}])=\left\{x \in Z[\sqrt{3}] / \forall n \in N, n \geq 2, x^{n} \in P[\sqrt{3}]\right\}
$$

Proposition 4.2. The set $P[\sqrt{3}]$ is included strictly to the set $\mathrm{N}(Z[\sqrt{3}], P[\sqrt{3}])$, so 


$$
P[\sqrt{3}] \subset \mathrm{N}(Z[\sqrt{3}], P[\sqrt{3}]) .
$$

\section{This since:}

1. $\forall p \in P[\sqrt{3}], \forall n \in N, n \geq 2$, we have $p^{n}=(2 x)^{n}=2\left(2^{n-1} x^{n}\right)=2 y \in P[\sqrt{3}]$, because being $Z[\sqrt{3}]$ the ring, $y=2^{n-1} x^{n} \in Z[\sqrt{3}]$. So,

$$
\forall p \in P[\sqrt{3}], p^{n} \in P[\sqrt{3}] \text { for } \forall n \in \mathrm{N}, n \geq 2 \text {. }
$$

According to (1) this implies $p \in \mathrm{N}(Z[\sqrt{3}], P[\sqrt{3}])$, i.e.

$$
P[\sqrt{3}] \subseteq \mathrm{N}(Z[\sqrt{3}], P[\sqrt{3}]) .
$$

2. We take $x=a+b \sqrt{3} \in Z[\sqrt{3}]$, where $a=2 r+1, b=2 s+1$ and $r, s \in Z$.

Since $a, b$ aren't even numbers, so $x \notin P[\sqrt{3}]$. However $x^{2} \in P[\sqrt{3}]$, because

$$
\begin{gathered}
x^{2}=(a+b \sqrt{3})^{2}=a^{2}+2 a b \sqrt{3}+3 b^{2}=(2 r+1)^{2}+2(2 r+1)(2 s+1) \sqrt{3}+3(2 s+1)^{2}= \\
=4 r^{2}+4 r+1+2(2 r+1)(2 s+1) \sqrt{3}+3\left(4 s^{2}+4 s+1\right)= \\
=4 r^{2}+12 s^{2}+4 r+4 s+4+2(2 r+1)(2 s+1) \sqrt{3}= \\
=2\left[\left(2 r^{2}+6 s^{2}+2 r+2 s+2\right)+(2 r+1)(2 s+1) \sqrt{3}\right] \in P[\sqrt{3}] .
\end{gathered}
$$

With mathematical induction is proved that: $x^{n} \in P[\sqrt{3}]$ for $\forall n \in N, n \geq 2$. So,

$$
\forall x=(2 r+1)+(2 s+1) \sqrt{3} \in Z[\sqrt{3}], x^{n} \in P[\sqrt{3}] \text { for } \forall n \in N, n \geq 2
$$

From (2) and (3), derives that: $P[\sqrt{3}] \subset \mathrm{N}(Z[\sqrt{3}], P[\sqrt{3}])$

Proposition 4.3. In $N(Z[\sqrt{3}], P[\sqrt{3}])$ take part only two type of numbers from $Z[\sqrt{3}]$, and exactly 1) numbers of the form $a+b \sqrt{3}$, where $a=2 r, b=2 s$ and $r, s \in Z$

2) numbers of the form $a+b \sqrt{3}$, where $a=2 r+1, b=2 s+1$ and $r, s \in Z$.

It is clear that in the ring $Z[\sqrt{3}]$ take part these type numbers: 
1. $a+b \sqrt{3}$, where $a=2 r, b=2 s$ and $r, s \in Z$;

2. $a+b \sqrt{3}$, where $a=2 r+1, b=2 s+1$ and $r, s \in Z$;

3. $a+b \sqrt{3}$, where $a=2 r+1, b=2 s$ and $r, s \in Z$;

4. $a+b \sqrt{3}$, where $a=2 r, b=2 s+1$ and $r, s \in Z$.

From (3) derives that numbers of type 1) and 2) are numbers in $\mathrm{N}(Z[\sqrt{3}], P[\sqrt{3}])$, whereas numbers of type 3$)$ and 4$)$, don't take part in $N(Z[\sqrt{3}], P[\sqrt{3}])$, this could be proved in direct way.

Proposition 4.4. The set $\mathrm{N}(Z[\sqrt{3}], P[\sqrt{3}])$ is the right ideal of ring $Z[\sqrt{3}]$, connected with a its right ideal $P[\sqrt{3}]$.

Proof. 1. For every $z_{1}, z_{2} \in \mathrm{N}(Z[\sqrt{3}], P[\sqrt{3}])$ that are of the first type, we have:

$$
\begin{aligned}
z_{1}-z_{2} & =\left(2 r_{1}+2 s_{1} \sqrt{3}\right)-\left(2 r_{2}+2 s_{2} \sqrt{3}\right)=2\left(r_{1}-r_{2}\right)+2\left(s_{1}-s_{2}\right) \sqrt{3}= \\
& =2\left[\left(r_{1}-r_{2}\right)+\left(s_{1}-s_{2}\right) \sqrt{3}\right]=2 x \in P[\sqrt{3}] .
\end{aligned}
$$

For every $z_{1}, z_{2} \in \mathrm{N}(Z[\sqrt{3}], P[\sqrt{3}])$ that are of the second type, we have:

$$
\begin{aligned}
z_{1}-z_{2} & =\left(2 r_{1}+1\right)+\left(2 s_{1}+1\right) \sqrt{3}-\left[\left(2 r_{2}+1\right)+\left(2 s_{2}+1\right) \sqrt{3}\right]=2\left(r_{1}-r_{2}\right)+2\left(s_{1}-s_{2}\right) \sqrt{3}= \\
& =2\left[\left(r_{1}-r_{2}\right)+\left(s_{1}-s_{2}\right) \sqrt{3}\right]=2 x \in P[\sqrt{3}] .
\end{aligned}
$$

If $z_{1}$ is of the first type and $z_{2}$ is of the second type i.e.

$z_{1}=2 r_{1}+2 s_{1} \sqrt{3}$ and $z_{2}=\left(2 r_{2}+1\right)+\left(2 s_{2}+1\right) \sqrt{3}$, then

$z_{1}-z_{2}=\left[2\left(r_{1}-r_{2}-1\right)+1\right]+\left[2\left(s_{1}-s_{2}-1\right)+1\right] \sqrt{3}=\left(2 r_{3}+1\right)+\left(2 s_{3}+1\right) \sqrt{3}$, being number of the second type take part in $\mathrm{N}(Z[\sqrt{3}], P[\sqrt{3}])$. Finally, if $z_{1}$ is of second type and $z_{2}$ is of first type, in analogous way could be said again $z_{1}-z_{2} \in \mathrm{N}(Z[\sqrt{3}], P[\sqrt{3}])$.

As conclusion, $\forall z_{1}, z_{2} \in \mathrm{N}(Z[\sqrt{3}], P[\sqrt{3}]), z_{1}-z_{2} \in \mathrm{N}(Z[\sqrt{3}], P[\sqrt{3}])$. 
2. Also, $\forall z \in \mathrm{N}(Z[\sqrt{3}], P[\sqrt{3}]), \forall x \in Z[\sqrt{3}]$ follows that $z x \in \mathrm{N}(Z[\sqrt{3}], P[\sqrt{3}])$. This since $z \in \mathrm{N}(Z[\sqrt{3}], P[\sqrt{3}])$ and $z$ is of first type, then we have $z=2 r+2 s \sqrt{3}$, where $r, s \in Z$ and since $x \in Z[\sqrt{3}]$, we have $x=a+b \sqrt{3}$, where $a, b \in Z$.

Then, $z x=2(a r+3 s b)+2(b r+a s \sqrt{3})=2 m+2 n \sqrt{3} \in \mathrm{N}(Z[\sqrt{3}], P[\sqrt{3}])$.

Now, we get the case when $z$ is of second, so, $z=(2 r+1)+(2 s+1) \sqrt{3}$, where $r, s \in Z$ and since $x \in Z[\sqrt{3}]$, we have $x=a+b \sqrt{3}$ where $a, b \in Z$.

$$
z x=[(2 r+1)+(2 s+1) \sqrt{3}](a+b \sqrt{3})=(2 r a+a+6 s b+3 b)+(2 r b+b+2 s a+a) \sqrt{3} .
$$

Being even or odd number of expressions $2 r a+a+6 s b+3 b$ and $2 r b+b+2 s a+a$ and depends on $a+3 b$, respectively $a+b$, then we get cases:

i) When $a, b$ are even numbers derives that $a+3 b$ respectively $a+b$ is even, hence $z x$ is of first type, so $z x \in \mathrm{N}(Z[\sqrt{3}], P[\sqrt{3}])$.

ii) When $a, b$ are odd numbers derives that $a+3 b$ respectively $a+b$ is even, hence $z x$ is of first type, so $z x \in \mathrm{N}(Z[\sqrt{3}], P[\sqrt{3}])$.

iii) When $a$ is odd number and $b$ is even number derives that $a+3 b$ respectively $a+b$ is odd, hence $z x$ is of second type, so $z x \in \mathrm{N}(Z[\sqrt{3}], P[\sqrt{3}])$.

iv) When $a$ is even number and $b$ is odd number derives that $a+3 b$ respectively $a+b$ is odd, hence $z x$ is of second type, so $z x \in \mathrm{N}(Z[\sqrt{3}], P[\sqrt{3}])$.

We get $\forall z \in \mathrm{N}(Z[\sqrt{3}], P[\sqrt{3}])$ and $\forall x \in Z[\sqrt{3}]$ we have: $z x \in \mathrm{N}(Z[\sqrt{3}], P[\sqrt{3}])$.

From formula (1) and the proposition 4 derives that $\mathrm{N}(Z[\sqrt{3}], P[\sqrt{3}])$ is right nil ideal of ring $Z[\sqrt{3}]$ connected with a right ideal $P[\sqrt{3}]$.

Beside subset $\mathrm{N}(Z[\sqrt{3}], P[\sqrt{3}])$ of ring $Z[\sqrt{3}]$ we examine the subsets:

$$
\begin{aligned}
& I_{1}=\{a+b \sqrt{3} / a=2 r, b=2 s \text { and } r, s \in Z\} \\
& I_{2}=\{a+b \sqrt{3} / a=2 r+1, b=2 s+1 \text { and } r, s \in Z\} .
\end{aligned}
$$


Since $I_{1}=P[\sqrt{3}]$, from proposition 4.2 derives that $I_{1}$ is right nilideal of ring $Z[\sqrt{3}]$ connected with a $P[\sqrt{3}]$. Since $I_{1}+I_{2}=\mathrm{N}(Z[\sqrt{3}], P[\sqrt{3}])$, from proposition 4.4 and $I_{1}+I_{2}$ is right nil ideal of ring $Z[\sqrt{3}]$ connected with a $P[\sqrt{3}]$. Having in mind the proposition 4.3, they are only ones such nilideals.

As conclusion, the nilideal $\mathrm{N}(Z[\sqrt{3}], P[\sqrt{3}])$ is the sum of all right nilideals of ring $Z[\sqrt{3}]$ connected with a right ideal $P[\sqrt{3}]$. Thus, the largest nilideal of ring $Z[\sqrt{3}]$ connected with a right ideal $P[\sqrt{3}]$, according to the definition of the upper nilradical connected with a right ideal, $\mathrm{N}(Z[\sqrt{3}], P[\sqrt{3}])$ is the upper nilradical of ring $Z[\sqrt{3}]$ connected with a right ideal $P[\sqrt{3}]$.

Remark: We have generalized the above construction for the case $\mathbf{Z}[\sqrt{p}]$, where $p \in N \backslash\{2\}$ is a simple scalene number. 


\section{References}

1. B. J. Gardner, R. Wiegandt, Radical Theory of Rings, Marcel Dekker, Inc. New YorkBasel, 2004

2. N. J. Divinsky, Rings and Radicals, 1965

3. Андрунакиевич В. А, Рябухин Ю. М., Радикаль алгебр и структурная теория, М. Наука, 1979

4. A. Jusufi, Radikalet e algjebrave lidhur me një ideal te djathtë, punim magjistrature, Prishtinë, 2006

5. M.Ferrero and E.R. Puczylowski, The Singular Ideal and Radicals, J.Austral. Math. Soc. $64-1998$

6. A. Jusufi, K.Filipi, The upper nilradical connected with a right ideal in the ring of the triangular nxn-matrices on the field of the real numbers, Mathematica Macedonica ISSN1409-9721, vol.5-2007,(43-56).Skopje

7. A. Jusufi , Radikali lokalisht nilpotent lidhur me një ideal të djathtë, Buletini shkencor UNIEL-Proceedings, viti XI-2007/3, Elbasan-2007,(52-61).

8. A. Jusufi, K. Filipi, Radikali $i$ Jacobsonit. Ndërtimi, relativiteti, trashëgimia dhe fortësia e tij, The scientific bulletin UNIEL-Proceedings, viti XII, 2008/3, Elbasan2008,(69-84).

9. A.Jusufi, K. Filipi, Nilradikali i sipërm lidhur me një ideal të djathtë në unazën e matricave reale trekëndëshe të rendit të tretë, Buletini shkencor UNIEL

10. А. Јусуфи, К. Филипи, Горниот нилрадикал сврзан со еден десен идеал на прстено $(\mathbf{Z}[\sqrt{2}],+, \cdot)$-Математички Билтен ISSN 0351-336X, Скопје-2009.

11. А. Јусуфи, К. Филипи, Dolen нилрадикал сврзан со еден ednostran идеалМатематички Билтен ISSN 0351-336X, Скопје-2010. 